\title{
Merayakan Records in Contexts: \\ Latar dan Kandungan Standar Deskripsi Arsip Terbaru Keluaran International Council on Archives
}

\author{
Raistiwar Pratama \\ Arsip Nasional Republik Indonesia
}

\begin{abstract}
This article aims to describe several major themes of a newly released standard by International Council on Archives, namely Records in Contexts (RiC). More than mere comprising all four existing standards, $\mathrm{RiC}$ to uplift function and activity of records within their own origin contexts. Almost three decades after the publication of the first standard (General International Standard Archival Description [ISADG]), RiC has developed its own understanding about major archival themes such as provenance, fonds, and original order, to comply with a very recent development of rapidly changing medium by questioning the famous adagium "medium is the message" back in 1970's and reading machines that are understood as being separated from the records itselves. Either records or archives have shifted from texts to contexts.
\end{abstract}

Submitted: $2 / 11 / 2020$

Received: 28/12/2020

*Correspondence:

Raistiwar Pratama raistiwar.pratama@anri.go.id

KEYWORDS:

arsip

konteks

standar

\section{INTISARI}

Artikel ini menguraikan pokok-pokok gagasan standar terbaru keluaran International Council on Archives, bertajuk Records in Contexts. Tidak hanya merangkum keempat standar yang ada, standar ini mengutamakan fungsi dan kegiatan setiap arsip sesuai sejarah penciptaannya. Setelah hampir tiga dasawarsa setelah standar pertama (General International Standard Archival Description [ISADG]) terbit, standar ini telah mengembangkan pengertiannya sendiri mengenai antara lain asal-usul, fonds, dan aturan asli, menyesuaikannya dengan perkembangan medium informasi yang begitu cepat teralihmediakan sembari mempertanyakan adagium "medium adalah informasi" sejak dasawarsa 1970-an dan perangkat keterbacaan yang dipahami sebagai bukan-arsip. Arsip telah berpindah dari teks menuju konteks. 


\section{PENDAHULUAN}

Pada Februari 2020, International Council on Archives (ICA) resmi merilis kedua bagian dari Records in Contexts (RiC): A Conceptual Model for Archival Description dan An Ontology. Setelah hampir dua tahun lamanya, Experts Group on Archival Description (EGAD), melanjutkan kerja Committee on Best Practices and Standards, bentukan ICA Programme Commission berhasil mempersiapkan "...suatu standar deskriptif yang menyelaraskan, menggabungkan, dan mengembangkan empat standar sebelumnya" (Pitti et.al., 2014: 1). Duapuluh enam tahun sejak ICA pertama kali menerbitkan edisi pertama General International Standard Archival Description (ISADG), RiC merumuskan ulang apa yang dimaksud dengan "deskripsi arsip" dan menekankan pentingnya latar penciptaan dalam pengarsipan, sebagaimana tersurat pada penggunaan lema "records" pada judul dan pencantumannya dalam uraian, sehingga kelak berdampak pada akses sepanjang masa sekalipun pencipta arsip telah tiada.

Dari keempat standar yang telah diterbitkan, International Standard for Describing Functions (ISDF) merupakan standar yang paling berpengaruh terhadap RiC. Tidak dipungkiri ICA jelas mempersiapkan kelahiran RiC dengan menjadikan "functional provenance" dan "series systems" sebagai kerangka pemikirannya. Fungsilah yang melatarbelakangi serta kelak menciptakan, memelihara, dan menangkap kegiatan dan transaksi. Keberadaan fungsi lebih luwes daripada struktur dan bentuk pencipta arsip. Fungsi bisa berdiri sendiri atau menjadi struktur itu sendiri. Pun, fungsi bisa terdiri dari beberapa (sub-) fungsi dan berada di bawah struktur tunggal. Apabila struktur dibentuk untuk menjalankan fungsi kelembagaan maka sudah semestinya tidak ada kesenjangan antara struktur dan fungsi kelembagaan. Struktur kelembagaan hilang, bergabung, dan berfungsi, sedangkan fungsi bertumbuh dan berkembang. Dus, latar atau konteks penciptaan, dengan menggunakan lema "records", menandai pergeseran paradigma dari hilir ke hulu, dari statis ke dinamis, dan dari pasif menjadi aktif. Hubungan pengarsipan yang langgeng adalah hubungan antara arsip dan fungsi penciptaan. Records in Contexts (RiC) hadir ketika medium informasi dan piranti keterbacaan sedang berubah dan perubahannya pun cepat, bahkan ketika artikel ini ditulis. Arsip, dengan segala lema yang dipilih, apakah rekod, dokumen, atau tetap arsip, bukan hanya informasi dan tidak semua informasi dapat menjadi arsip. Terutama tanpa akses berkelanjutan sekalipun pencipta arsip telah tiada, maka informasi tersebut tidak dapat menjadi arsip. Standar ini lahir untuk mengemukakan "bahasa yang sama" dengan berbagai medium sebagaimana ISAD-G pernah rumuskan, para pencipta bukan-negara sebagaimana International Standard Archival Authority Records for Corporate Bodies, Persons and Families (ISAAR) rumuskan, lembaga penyimpanan sebagaimana International Standard for Describing Institutions with Archival Holdings (ISDIAH) rumuskan, dan beragam wali (custody) dan pemilik (owner) sebagaimana ISDF rumuskan. Penelitian ini merumuskan permasalahan dalam dua pertanyaan utama:

1. Mengapa Experts Group on Archival Description - International Council on Archives menyusun Records in Contexts?

2. Apa saja dan bagaimana perumusan tema pokok Records in Contexts?

Artikel ini bertujuan untuk memperkenalkan standar tunggal terbaru keluaran ICA kepada "komunitas kearsipan", RiC menyebutkan dua komunitas: "archival community" dan "records management community", di Indonesia.

Indonesia melalui Kamus Besar Bahasa Indonesia menerakan beberapa kata yang sinonim dengan "standard ( $n$ )", yaitu pedoman, panduan, manual, dan standar. Secara linear, baik "records" maupun "archives" lebih merupakan titik berangkat yang berada dalam bentangan spektrum menurut ICA, bukan perbedaan dikotomis. Sebagaimana 
pendekatan "rangkaian pengarsipan" (records continuum) yang tidak menggantikan "daur hidup" (life cycle), melainkan melengkapi pendekatan atau teori kearsipan. Kesamaan keduanya, ICA tegaskan dengan mendefinisikan karakteristik arsip (archives) sebagaimana International Organization for Standardization (ISO) mendefinisikan arsip otoritatif (authoritative records). Keduanya, "archive" menurut ICA dan "records" menurut ISO, harus memenuhi empat syarat (ISO 15489-1:2016 dan SNI 8642:2018, serta https://www.ica.org/en/what-archive, diakses 18 Februari 2020): authentic (autentik), andal (reliable), utuh (integrity), dan dapat terpakai (useable).

Apabila "record(s)" selalu merujuk pada kekinian atau serupa dengan informasi terbarukan dan merupakan ranah penciptaan, maka "archives" tidak melulu merupakan salah satu hasil dari penyusutan dan memiliki beberapa padanan kata, tidak hanya "arsip statis" sebagaimana bahasa Indonesia menerjemahkannya. Beberapa padanan tersebut antara lain "secondary valued records", "contemporary records", "archival records", "archival documents," dan "historical records". Baik "record" (ISAD-G 2nd edition, 2000: 11; RiC $1^{\text {st }}$ edition, 2016: 13) maupun "archives" atau "an archive" (https://www.ica.org/en/what-archive, diakses pada 18 Februari 2020), keduanya ICA gunakan.

Menuruti uraian Archiefterminologie voor Nederland en Vlanderen (2007), kita temukan bahwa "dinamis", "statis", dan di antara keduanya "semi-statis" merupakan fase atau tahap dalam pendekatan daur hidup. Setiap arsip menuruti daur hidupnya melewati tiga fase: dynamische, semi-statische, dan statische. Polemik wacana "arsip" dan/ atau "rekod" pernah, sedang, dan akan terus-menerus terjadi (Pratama, 2017: 38 - 40). Tanpa harus memilih salah satu, bahasa merupakan medan tawar-menawar. Pengguna bahasa itu sendiri yang berhak menentukan, bukan pemerintah, bukan pula komunitas, apalagi seseorang. Konsensus atau kesepakatan, sebagaimana salah satu prinsip penyusunan standar ISO, kiranya merupakan proses panjang. Sebagaimana ISO, ICA tidak membedakan definisi keduanya. Sekalipun ICA dan ISO menggunakan lema bahasa Inggris yang berbeda. Bahkan RiC sekali waktu masih menggunakan frasa "recorded information". Sedikit berbeda, ISO menggunakan frasa "records management sedangkan ICA melalui RiC menggunakan frasa "management of records".

Apa yang dimaksudkan dengan "konteks" adalah latar sejarah penciptaan dan penggunaan arsip. Konteks bagi arsip terkait erat dengan prinsip asal-usul yang terdiri dari dua "respects for": "des fonds" dan "original order". Pemberkasan yang selama ini terjadi hanya karena korespondensi surat masuk dan surat keluar justru meniadakan kenyataan bahwa pencipta arsip itu jamak, sehingga penciptaan lebih mungkin menangkap latar pengarsipan. Keragaman "para pencipta arsip" tersebut tidak tercermin dalam pemahaman mengenai apa itu "fonds". Sekalipun terlihat bahwa struktur kelembagaan yang menciptakan dan memberkaskan arsip, padahal sejatinya fungsi-lah atau struktur pengarsipan suatu lembaga yang melakukannya. "Fonds" pada "respect des fonds" berbeda dengan "fonds" pada kerja deskripsi berjenjang (multilevel description). Untuk memahami fungsi, maka pendekatan "series" atau acapkali disebut Australian Series System lebih sesuai sehingga deskripsi dapat menangkap dimensi-dimensi pengarsipan yang di Kanada dikenal sebagai "total archives" karena menerima semua perilaku pengarsipan, bukan hanya negara. Agregasi, lebih daripada pemberkasan yang cenderung "menunggalkan" pencipta arsip, merupakan salah satu kata kunci memahami konteks pengarsipan karena berusaha menangkap berbagai dimensi yang melingkupinya.

Mengikuti standar bukan merupakan suatu keharusan baku tetapi sebagai salah satu ilmu dari ilmu terapan, Ilmu Kearsipan mendapatkan pengakuannya dari kemampuan menyelesaikan permasalahan yang sekalipun praktis tetap berdampak 
teoretis dan filosofis. Standar kearsipan menjabarkan dan menerapkan prinsip-prinsip kearsipan. Apabila terdapat kesenjangan, penyesuaian subtansi standar terus menerus dilakukan seraya mengembangkan pemahaman terbarukan mengenai prinsip-prinsip kearsipan. Terhadap standar, prinsip-prinsip tersebut diuji ketangguhannya menghadapi perubahan. Apakah lekang oleh waktu, bersenyawa dengan perubahan, atau bertahan mengikuti apa yang generasi awal definisikan?

Secara semantik standar, manual, dan pedoman merupakan sinonim satu sama lain (salah satunya lihat $A$ Comprehensive Indonesian-English Dictionary: ${ }^{0} 5^{0},{ }^{1} 67$, 957). Tidak ada kesepakatan untuk membedakan ketiganya, terutama di komunitas kearsipan Indonesia. Ini serupa dalam bahasa Inggris, standard antara lain serupa dengan benchmark, criterion, model, dan ordinary (The American Heritage College Thesaurus: ${ }^{10} 5$ ). Dari ketiga de 1 inisi yang Society of American Archivist terakan, standard sebagai "An international, national, or industry agreement that establishes qualities or practice in order to achieve common goals" merupakan definisi yang sejalan dengan artikel ini. Standar bukan benda mati dan siap saji, sebagaimana Dutch Trio tuliskan dalam Dutch Manual dan ICA tuliskan dalam standar-standar kearsipan keluarannya. Seperti prinsip kearsipan, standar pun berkembang. Demikian pula standar tunggal terbaru keluaran ICA ini.

\section{METODE PENELITIAN}

Kajian standar kearsipan terbaru keluaran ICA merupakan kajian pustaka. Penelitian sebagaimana tulisan ini uraikan menjadikan standar tunggal terbaru dan empat standar yang telah ada keluaran ICA sebagai pokok kajian. Perbandingan (keserupaan dan perbedaan) dengan standar-standar lain keluaran ISO dan berbagai negara juga diuraikan apabila diperlukan. Kajian kepustakaan maka dari itu merupakan kemestian.

\section{HASIL DAN PEMBAHASAN Menyejarahkan Konteks}

Pembahasan artikel ini terdiri dari empat pokok bahasan sebagaimana EGAD uraikan dalam RiC. Keempatnya adalah asal-usul, entitas, properti dan atribut, serta relasi. Setiap pokok bahasan sedapat mungkin, penulis uraikan contoh dari konteks dan di Indonesia. Terdapat dua bagian RiC: A Conceptual Model for Archival Description (RiCCM) dan Ontology (RiC-0). Versi kedua (selanjutnya RiC-CM V.2) bagian pertama telah terbit pada 12 Desember 2019, setelah masukan dari berbagai kalangan di berbagai negara diterima pada versi pertama (selanjutnya RiC-CM V.1) yang terbit pada 29 Agustus 2016 (https://www.ica.org/en/egad-ric-conceptual-model, diakses pada 3 Maret 2020). Berbeda dengan bagian pertama yang telah dua kali terbit, versi pertama bagian kedua (RiC-O atau RiC OWL) terbit secara dalam jaringan pada 12 Desember 2019 (https://www.ica.org/en/public-release-of-records-in-contexts-ontology-v01and-records-in-contexts-conceptual-model-v02, terakhir diakses pada 3 Maret 2020).

Pada Februari 2020, kedua bagian RiC resmi terbit bersamaan. Peluncuran perdananya berlangsung di Paris pada 28 Januari 2020 atas upaya Archives nationales (https://francearchives.fr/fr/actualite/213134416, diakses 3 Maret 2020). Paris Prancis merupakan tempat di mana salah satu anggota EGAD, Florence Clavaud, seorang arsiparis Archives nationales dan pengajar École nationale des chartes, bermukim. École nationale des chartes juga merupakan tempat di mana Samuel Muller pernah mempelajari "respect des fonds" pada akhir abad XIX hingga kemudian menuangkannya ke dalam Handleiding voor Ordenen en Beschrijven atau lebih dikenal dengan Dutch Manual (Pratama, 2017).

Peluncuran tersebut bertajuk "Les métadonnèes archivistiques en transition: Le nouveau cadre normatif, les enjeux et les premières réalisations" (Metadata Kearsipan 
dalam Transisi: Kerangka Standar Baru, Permasalahan, dan Pencapaian Perdana). Paris juga merupakan tempat di mana sekretariat TC 46 bertempat, di kawasan Association française de normalisation (https://normalisation.afnor.org/, diakses 25 Februari 2020).

\section{Empat Pokok Bahasan}

Tidak hanya untuk "traditional analogue records" dan "non-digital records", RiC, terutama bagian keduanya (RiC-0), juga merupakan standar deskripsi untuk "electronic records" dan mungkin mencakup "digital records" (RiC-CM, 2016: 3). Pembahasan terutama menyasar kedua versi RiC-CM karena standar tunggal inilah yang merangkai ulang keempat standar sebelumnya lalu menyesuaikannya dengan perubahan kiwari. Adapun RiC-O merupakan sebentuk sistem informasi pengarsipan untuk representasi RiC-CM di ranah pengarsipan digital. Pada bagian kedua RiC inilah, lema "archival record resource" mengemuka. Pertama kali dikembangkan sejak 2017 di Perancis. (http://piaaf.demo.logilab.fr/, terakhir diakses 5 Maret 2020).

\section{Asal Usul}

Apa yang menjadi keunikan (Ilmu) Kearsipan adalah prinsip asal usul. Menurut RiC-CM V.1, prinsip tersebut mengharuskan setiap arsip memiliki dua syarat: respect des fonds dan respect for the original order. Inilah prinsip kearsipan (archival principles), bukan prinsip pengelolaan arsip (records management principles). Sekalipun membedakan keduanya, records dari archives dan sebaliknya, perbedaan keduanya lebih karena proses yang semestinya sinambung dan retrospektif. Apa yang terjadi pada records kelak berdampak pada archives. Kecuali mencantumkan dua syarat utama prinsip asal-usul, prinsip tersebut justru tidak didefinisikan.

Prinsip ini berdampak besar pada kerja archivists dan records managers, serta penilaian untuk penyusutan dan memori kolektif. Sekalipun di Indonesia, arsiparis harus menguasai sekaligus baik dinamis maupun statis namun perspektif arsiparis masih melihat dari sudut statis atau ranah preservasi dan akses jangka panjang. Sulit, kalau tidak dibilang mustahil, mendapatkan arsiparis yang mampu melihat dari sudut dinamis atau ranah penciptaan dan penggunaan. Kerja arsiparis dewasa ini dan mendatang lebih daripada sekadar deskripsi tetapi pengolahan arsip statis yang mencakup mengolah informasi (description) dan menempatkan medium (arrangement). Kedua perspektif inilah yang disebut perspektif pengarsipan, proses; bukan hanya kearsipan, hasil akhir. Perspektif hilir dan hulu yang arusnya bertemu di riam-riam sungai proses pengarsipan. Sudut pengarsipan keduanya saling melampaui satu sama lain.

Mengutip Daniel Pitti (2017), prinsip asal-usul telah menjadi "general international consensus" namun terdapat "historical and cultural differences in understanding" di setiap negara atau kawasan yang berusaha memahaminya apalagi menerapkannya. Inilah prinsip yang terus-menerus berkembang dan mengilhami peralihan dari multilevel description ke multidimensional description. Arsip bukan merupakan hasil salah satu fungsi yang berada di suatu organisas, melainkan jejaring bermuka banyak yang melengkapi sudut-sudut wajah pengarsipan.

\section{Entitas}

Inilah yang penulis anggap sebagai pemaparan lanjutan "apakah fungsi itu". Melanjutkan semangat ISDF, RiC lebih lantang memaparkan "apakah entitas itu" dan bagaimana hubungannya dengan fungsi yang lebih dahulu didefinisikan. Pendekatan fungsi sebagaimana yang dipaparkan ISDF merupakan pengantar untuk memperkenalkan entitas pengarsipan kepada bukan ruang lingkup kearsipan saja. Fungsi menurut ISDF adalah:

“...Any high level purpose, responsibility or task assigned to the accountability 
agenda of a corporate body by legislation, policy or mandate. Functions may be decomposed into sets of co-ordinated operations such as subfunctions, business processes, activities, tasks or transactions," maka entitas adalah "...the primary objects of interest for professionals that manage records in the context of origin and use (records managers) or that manage records retained for long-term preservation and access (archivists)."

Lebih lanjut, pengertian entitas terdapat dalam salah satu bagian dari ISO 23081 yang sebelumnya lebih dikenal dengan ICA Req(-uirements). Apakah berdiri sendiri, bergabung bersama, kembali berpisah dengan struktur yang lebih rendah daripada sebelumnya; ataukah hilang sama sekali; ataukah lalu hidup kembali dengan fungsi serupa. Fungsi sejatinya hidup lebih lama daripada struktur yang menjalankan fungsi itu sendiri. Arsip (records dan archival records), dengan segala perubahan dan prosesnya, pun merupakan salah satu entitas. Entitas juga merupakan upaya menggantikan struktur atau setidaknya mengembalikan struktur sesuai fungsinya.

Entitas adalah "objek perhatian utama bagi praktisi yang mengelola arsip dalam konteks permulaan dan penggunaan bagi records managers, dan untuk preservasi jangka panjang dan akses bagi archivists". Ini bisa berarti apapun bagi kedua profesi tersebut. Bisa berarti elemen deskripsi, bisa juga berarti elemen metadata. Bisa berarti deskripsi jamak berjenjang, bisa juga berarti deskripsi jamak dimensi (multidimensional description).

Sekalipun entitas tetap hierarkis, namun kedudukan dan pergerakannya sangat lentur, sama sekali tidak bergantung pada struktur kelembagaan. Terdiri dari empat tingkat (four levels of entities hierarchy). Bandingkan dengan tingkat dalam deskripsi jamak berjenjang. Sekalipun keempatnya terhubung secara hierarkis dan tetap menggunakan lema "level" sebagaimana deskripsi jamak berjenjang ISAD-G, relasi yang dihubungkannya tidak tunggal dan sederhana. "Thing" atau "concept" terletak dan satu -satunya entitas yang berada di tingkat pertama sehingga definisinya pun meluas, bisa berarti apapun bentukan manusia, seperti konsep, wacana, dan pengalaman bersama. "Sesuatu" inilah yang merupakan entitas akar atau dasar.

Di bawah "sesuatu" terdapat record resource, instantion, agent, event, rule, date, dan place sebagai ketujuh entitas pada tingkat kedua. Tidak semua entitas pada tingkat kedua memiliki entitas bawahan. Selain instantion dan place, kelima entitas lainnya membawahi (beberapa) entitas. Record resource membawahi record set, record, dan record part. Agent membawahi person, group, position, dan mechanism. Event hanya membawahi activity. Rule pun hanya membawahi mandate. Adapun date, sebagaimana elemen deskripsi ISAD-G, mencakup single date, date range, dan date set. Pada tingkat keempat, group membawahi family dan corporate body. Record resource, instantion, agent, dan activity merupakan entitas inti, lebih sedikit daripada keenam elemen wajib ISAD-G. Enam entities lebih sedikit daripada RiC-CM V.1, RiC-CM V.2 mencantumkan 8 entities. Kedelapan entities tersebut adalah thing, record resource, instantion, agent, event, rule, date, dan place.

\section{Atribut (dahulu Properti)}

Setiap entity atau beberapa entities membawahi sekian attributes, menurut RiC-CM V.2, yang saling beririsan. Adapun RiC-CM V.1 tidak menyebutnya sebagai attributes, melainkan properties. Selalu dalam bentuk jamak, attributes membawahi atau, lebih tepatnya, menghubungkan titik-titik yang cakupannya lebih beragam daripada entities. Sekalipun beragam, attributes dapat merangkum banyak-apabila menggunakan kriteris ISAD-G-items di mana instansiasi memungkinkan tangkapan informasi tanpa bergantung pada medium perekaman.

Sebagaimana prinsip asal-usul, menurut paparan Bill Stockting (2017) yang 
masih menggunakan lema properties, attributes pun miliki dua dimensi: umum dan unik. Kiranya keduanya pun serupa dengan kriteria mendasar (essential) dan tambahan (optional) dalam ISAD-G. Dimensi umum mencakup elemen deskripsi yang wajib ada pada setiap tingkat deskripsi, seperti nama (pelaku, pencipta, dan organisasi), tempat, dan tanggal. Dimensi unik mencakup elemen yang hanya ada pada organisasi tertentu, di kawasan tertentu, dan pada suatu waktu.

Sewaktu masih bernama properties, misalnya, record set memiliki 4 tema properties: content, carrier, representation, dan management and use. Ketika bernama attributes, record set merupakan salah satu dari tiga (record part dan record itu sendiri) pembentuk record resource. Ketiga pembentuk record resource tersebut harus memenuhi tiga nama atribut: descriptive note, identifier, dan name.

Setiap atribut memiliki elemen deskripsi, seperti accrual, activity type, authenticity note, carrier extent, carrier type, certainty, classification, conditions of access, conditions of use, content type, coordinates, corporate body type, hingga bahasa dan technical characteristics.

\section{Relasi}

Hubungan atau relasi yang RiC kembangkan berbeda dari keempat standar sebelumnya. Relasi bermodelkan bagan (graph model) seperti Resource Description Framework (RDF), bukan hierarki-struktural seperti yang telah keempat standar kembangkan. Relasi ini kelak mengubah sistem pengarsipan seturut EAD dan EAC, sebagaimana terdapat dalam RiC Onthology. Relasi ini pada waktu bersamaan lebih sederhana karena lebih luwes namun lebih rumit karena menghubungkan setiap tingkat perkembangan, korespodensi, dan pemberkasan. Apa yang menjadi per tinggal bagi pengirim merupakan asli bagi penerima, dan merupakan tembusan bagi atasan serta salinan bagi siapa yang memerlukan. Apa yang menjadi bukti bagi salah satu atau bahkan kedua belah pihak, bisa jadi merupakan aset bagi pihak-pihak lain, bahkan merupakan informasi yang terbuka bagi pihak terdampak sekalipun tidak terlibat dan mungkin memberatkan posisi pihak-pihak yang terlibat. Secara retensi, bukti bisa musnah bagi satu pihak namun permanen bagi pihak lain.

Relasi berlangsung tidak hanya antara sesama entitas tetapi juga antara sesama atribut. Bisa hanya menghubungkan kedua belah pihak. Bisa juga menghubungkan banyak pihak. Dalam RiC-CM V.2, terdapat 13 corak relasi:

1. Relasi keseluruhan dengan setiap bagian (whole-part relations) sebagaimana pada deskripsi jamak berjenjang.

2. Relasi kelanjutan (sequential relations) antara satu agen dengan agen pelanjut, antara pencipta dengan penyimpan atau pemberi akses, dan antara wali (custody) dengan pencipta (creating agencies).

3. Relasi subjek (subject relations) antara arsip dengan pokok bahasan, antara series dengan files atau antara pemberkasan berkala dengan pemberkasan fungsi.

4. Relasi sesama record resource, seperti setiap tingkat perkembangan arsip yang saling terhubung.

5. Relasi record resource dengan instansiasi, seperti arsip bermediumkan kertas dengan bentuk konversi dan migrasinya atau hubungan alih media.

6. Relasi asal-usul (provenance relations), hubungan antara agen dengan arsip dengan kegiatan.

7. Relasi instansiasi, hubungan antara medium-medium yang melestarikan informasi dan akses.

8. Relasi manajemen, hubungan struktur jenjang pekerjaan dalam suatu organisasi.

9. Relasi antar-agen, hubungan keagenan yang memastikan setiap pelaku menangkap dan memberkaskan arsip.

10. Relasi kejadian, hubungan antara arsip dengan kejadian (event). Kejadian atau 
peristiwa berbeda dari kegiatan. Kejadian bersifat sekali terjadi, sedangkan kegiatan bersifat rutin. Relasi ini mengemuka pada sarana bantu temu kembali berbentuk guide.

11. Relasi aturan, hubungan antara agen dengan mandat.

12. Relasi waktu, hubungan antara record resource dengan tanggal.

13. Relasi spasial, hubungan antara tempat atau ruang dengan agen.

Pada dasarnya relasi bergerak secara berjenjang dari luas ke sempit dan atas ke bawah, namun relasi juga bergerak secara poly-hierarchical. Selain "terhubung dengan" dan "mengandung" informasi, relasi juga menangkap "bagian dari" dan merupakan "bawahan dari" atau merupakan "atasan dari" yang terus berubah dan bergerak.

Bagan 1.Tingkat dan Hubungan antar-entitas Records in Contexts

\begin{tabular}{|c|c|c|c|}
\hline \multicolumn{4}{|c|}{ RiC Entities Hierarchy } \\
\hline First Level & Second Level & Third Level & Fourth Level \\
\hline \multirow[t]{15}{*}{ RiC-E01 Thing } & \multirow[t]{3}{*}{ RiC-E02 Record Resource } & RiC-E03 Record Set & \\
\hline & & RiC-E04 Record & \\
\hline & & RiC-E05 Record Part & \\
\hline & RiC-E06 Instantiation & & \\
\hline & \multirow[t]{5}{*}{ RiC-E07 Agent } & RiC-E08 Person & \\
\hline & & RiC-E09 Group & RiC-E10 Family \\
\hline & & & RiC-E11 Corporate Body \\
\hline & & RiC-E12 Position & \\
\hline & & RiC-E13 Mechanism & \\
\hline & RiC-E14 Event & RiC-E15 Activity & \\
\hline & RiC-E16 Rule & RiC-E17 Mandate & \\
\hline & \multirow[t]{3}{*}{ RiC-E18 Date } & RiC-E19 Single Date & \\
\hline & & RiC-E20 Date Range & \\
\hline & & RiC-E21 Date Set & \\
\hline & RiC-E22 Place & & \\
\hline
\end{tabular}

\section{Sistem Informasi Pengarsipan: Sekilas Mengenai Record in Contexts-Ontology}

Aplikasi berubah lebih cepat, jauh lebih cepat daripada sistem informasi. Perubahan bukan berarti kelambanan, melainkan persyaratan dan pembatasan bagi sistem informasi untuk mampu menangkap inti pengarsipan sekalipun medium berubah. Maka dari itu, sistem informasi pengarsipan tampil begitu sederhana untuk memudahkan pengembangan sesuai dengan konteks pengarsipan.

Pada presentasi pertama kali soal RiC-0, Florence Clavaud (2017) memaparkan bahwa RiC-0 merupakan versi terbaca mesin (readable machine version) dan representasi baku (formal representation) dari RiC-CM dan sebelumnya ISAARCPF. Selain merupakan panduan untuk berbagi dan perluasan deskripsi arsip, serta kesempatan setiap komunitas-bukan hanya organisasi-untuk memberikan tanggapan dan keterlibatan.

Selain menggunakan piranti lunak Semantic Web Standard, RiC-O juga menggunakan RDF, RDFS (RDF Schema Language), dan OWL (Web Ontology Language). Metadata menjadi bahasan utama RiC bagian kedua ini. Metadata yang memungkinkan arsip dapat terus beralih-media, bermigrasi, berkonversi, dan terhubung dengan peladen repositori dan peladen emulasi; bahkan terhubung dengan bukan lembaga kearsipan atau repositori seperti museum, perpustakaan, dan galeri. Dunia kearsipan (archival world), demikian Clavaud, merupakan gambaran (graph) pelbagai entitas dan relasi. Seperti terlihat, konsep GLAM mendapatkan pembenaran 
teoretis komputasi dan semantik.

Apabila sistem arsip, membawahi sistem informasi, yang ISO kembangkan terdiri dari capture, manage, dan access; maka prinsip-prinsip pengembangan $\mathrm{RiC}-\mathrm{O}$ mencakup kelengkapan (completeness, bandingkan dengan integrity), kejelasan (clarity atau accuracy, bandingkan dengan reliable), dan keluwesan (flexibility, bandingkan dengan useability). Kecuali autentisitas, ketiga prinsip tersebut juga merupakan syarat-syarat arsip otoritatif (authoritative records), meminjam istilah dalam ISO 15489.

\section{KESIMPULAN}

Bukan hanya diciptakan, arsip memiliki konteks yang saling terkait dan terhubung (interrelated and interdependent contexts). Multidimensional description merupakan gabungan beberapa multilevel description. Inilah yang melatarbelakangi kerja ICA terutama Experts Group on Archival Description. Sekalipun ISAD-G masih digunakan sebagai standar umum, sebagaimana ketiga standar lainnya (ISDIAH, ISAAR-CPF, dan ISDF), RiC memudahkan kerja deskripsi arsip terutama arsip yang lahir dan berubah digital serta berada di ekosistem elektronik.

Lema yang bertebaran di RiC tidak lagi khas arsip seperti elemen deskripsi dan tingkat perkembangan tetapi menggunakan lema entitas, properti, atribut, dan relasi. Meskipun begitu prinsip pengarsipan tidak ditinggalkan melainkan disempurnakan dan disesuaikan konteks kekiniannya. Asal-usul dan aturan asli tetap menjadi prinsip dwitunggal pertama yang abadi. Pemberkasan pada tingkat series menentukan keberlangsungan penciptaan dan fungsi pengarsipan dan menentukan pembentukan struktur kelembagaan.

Standar tunggal keluaran ICA ini semakin mendekat kepada standar kearsipan keluaran ISO. Bahkan dapat disimpulkan bahwa standar keluaran kedua lembaga tersebut meleburkan batas-batas "archival records" dan "records" untuk mendapatkan perspektif pengarsipan yang utuh menyeluruh. Lebih dari sekedar pencantuman standar ISO sebagai rujukan di bibliografi keempat standar sebelumnya. Sekalipun perlu bahasan lanjutan dan terpisah, uraian RiC amat pekat memaparkan perihal "records" dan "archival record", bukan sebagai kesatuan yang berdiri sendiri tetapi saling melengkapi.

Berbeda dengan standar keluaran ISO ketika standar terbaru menggantikan standar lama, seperti 15489:2016 yang menambahkan dimensi aset pada definisi arsip, tidak seperti 15489-1:2001 ketika arsip hanya berdimensikan informasi dan bukti. Adapun standar-standar keluaran ICA yang terbaru tidak menggantikan standar lama, melainkan melengkapi, menyempurnakan, dan memperluas cakupannya.

\section{DAFTAR PUSTAKA}

Arsip Nasional Republik Indonesia. 2011. Pedoman Pengolahan Arsip Statis dalam Penyelenggaraan Jaringan Informasi Kearsipan Nasional. Jakarta: Pusat Pengkajian dan Pengembangan Sistem Kearsipan.

-----. 2016. Standar Deskripsi Arsip Statis. Jakarta: Direktorat Pengolahan Arsip Nasional Republik Indonesia.

Australian Society of Archivists. 2017. Response of the Australian Society of Archivists to the International Council of Archives Expert Group on Archival Description Records in Context-Conceptual Model. Australia: Australian Society of Archivists. 
Clavaud, Florence. 2017. "Presentation of Records in Contexts: Ontology," Records in Contexts. https://www.youtube.com/watch?v=ocAOghQ0ED8, diakses pada 12 September 2020.

Den Teuling, A. J. M. 2003. Archiefterminologie voor Nederland en Vlaanderen. 's Gravenhage: Stichting Archiefpublicaties.

Furner, Jonathan. 2016. "Records in Context" in Context: A Brief History of Data Modelling for Archival Description," Unpublished paper. Second draft. (http:// www.jonathanfurner.info/?page id=15, diunduh pada 3 Maret 2020).

International Council on Archives. 2000. General International Standard Archival Description. Second Edition. Paris: International Council on Archives.

-----. 2004. International Standard Archival Authority Record for Corporate Bodies, Persons and Families. Second Edition. Paris: International Council on Archives.

-----. 2007. International Standard for Describing Functions. First Edition. Paris: International Council on Archives.

-----. 2008. International Standard for Describing Institutions with Archival Holdings. First Edition. Paris: International Council on Archives.

-----. 2015. Records in Contexts: An International Standard for Archival Description, Progress Report. Cleveland: International Council on Archives.

-----. 2016. Records in Contexts: A Conceptual Model (Consultation Draft). $1^{\text {st }}$ Version. Paris: International Council on Archives.

----. 2019. Records in Contexts: A Conceptual Model (Consultation Draft Preview). $2^{\text {nd }}$ Version. Paris: International Council on Archives.

---. 2019. Records in Contexts: Ontology. $1^{\text {st }}$ Version. Paris: International Council on Archives.

Llanes-Padrón, Dunia; Pastor-Sanchez, Juan-Antonio. 2017. "Records in Contexts: the Road of Archives to Semantic Interoperability," Program Volume 95 Issue 8: $7^{21}$ 405.

McKemmish, Sue; Acland, Glenda; Ward, Nigel; and Reed, Barbara. 1999. "Describing Records in Context in the Continuum: The Australian Recordkeeping Metadata Schema," Archivaria Fall 8²: 7 - 37 (bisa juga diakses di http://staginginfotech.monash.edu.au/research/groups/rcrg/publications/archiv01.html, diakses pada 3 Maret 2020).

Muller, Samuel; Johan Feith and Robert Fruin (eds.). 1920. 2e editie. Handleiding voor het Ordenen en Beschrijven van Archieven. Groningen: Erven B. van der Kamp.

Pitti, Daniel; Florin-Popovici, Bog; Stocking, William; and Clavaud, Florence. 2014. "Experts Group on Archival Description: Interim Report," Girona: 1 - 11.

Pitti, Daniel. 2017. "Presentation of Records in Contexts," Records in Contexts. https:// www.youtube.com/watch?v=YcoosGnrlsI\&pbjreload=101, diakses pada 12 September 2020.

Pitti, Daniel; Stocking, William; and Clavaud, Florence. 2018. "An Introduction to "Records in Contexts": An Archival Description Draft Standard," Comma Issue 5-2 Volume 2016: 173 - 188. 
Pratama, Raistiwar. 2017. "Archives and the Archipelago: Influence of Dutch Archivistiek on Indonesian Archival Practices". Unpublished Master Thesis, University of Leiden.

Stockting, Bill. 2017. "Presentation of the Conceptual Model." Records in Contexts. https://www.youtube.com/watch?v=b0xSIzeCvlI, diakses pada 12 September 2020. 